\title{
CULTURAS MINERAS Y PROYECTOS VITALES EN CIUDADES DEL CARBON, DEL NITRATO Y DEL COBRE EN CHILE ${ }^{1}$
}

\author{
MINING CULTURES AND VITAL PROJECTS IN CITIES OF COAL, \\ NITRATE AND COPPER IN CHILE
}

\author{
Juan Carlos Rodríguez Torrent ${ }^{1}$, Pablo Miranda Bown ${ }^{2}$ y Patricio Medina Hernández ${ }^{3}$
}

\begin{abstract}
En las ciudades mineras de Chile, del carbón, nitrato y cobre, encontramos una identidad social particular. La reproducción social no está dada sólo por la explotación del mineral, sino por la existencia de ciudades mineras asociadas a una población concentrada, cautiva y estable. Los ingentes desarrollos de la minería en el siglo veinte, la economía globalizada, las crisis y ciclos de los minerales, las fluctuaciones en los valores, la necesidad de eficacia y rentabilidad de las compañías han convertido a estas ciudades en disfuncionales a los objetivos empresariales y han cuestionado los modos de vivir y las identidades. Las soluciones planteadas han sido reconvertir a las poblaciones, cerrar y abandonar dichas ciudades, transformarlas en campamentos o patrimonializarlas. Así, se ha roto la continuidad de una cultura del trabajo, los tejidos sociales y las formas de socialización de sus habitantes. A partir de distintos trabajos de campo de los autores sobre ciudades mineras, y el registro de nuevos antecedentes etnográficos, etnológicos e históricos en las regiones II, III, VI y VIII, se exploraron algunas de las transformaciones y declinación de los formatos urbanos de estos asentamientos y su giro hacia una dimensión más patrimonial del lugar, como una respuesta a las nuevas características del capital.
\end{abstract}

Palabras claves: cultura del trabajo, modo de vida, ciclo minero, imaginario, patrimonialización.

In the coal, nitrate and copper mining towns of Chile, we find a particular social identity. Social reproduction arises not only from mineral exploitation, but from the existence of mining towns associated with a concentrated, captive and stable population. The enormous developments in mining during the $20^{\text {th }}$ century, the globalized economy, the crises and cycles of minerals, the fluctuations in prices, the necessity for efficiency and profitability of the companies have made these towns dysfunctional for business objectives and have put the peoples' ways of life and identities have been put into question. The proposed solutions have been to restructure the population and close and abandon the cities, transforming them into camps or turning them into heritage. Consequently, the continuity of a work culture, the social tissue and forms of socialization of the inhabitants have been broken. Some of the transformations and declines in urban formats of these settlements and the shift toward viewing them as heritage are examined based on the authors'varied fieldwork on mining towns as well as new ethnographic, ethnological and historical records in II, III, VI and VIII regions, as a response to the new features of capital.

Key words: Work culture, way of life, mining cycle, imaginary, heritage-making.

\section{Imaginarios Mineros}

La construcción de Chile, así como el de su imaginario, se realiza en los últimos dos siglos, principalmente, a partir de la explotación de recursos mineros, de la movilización de grandes contingentes de trabajadores y de la inversión de recursos privados para la extracción del mineral. Esto ha ocurrido con el nitrato, el que en 1910 con sus tributos llegó a contribuir al erario nacional en una cifra cercana al 60\%; el carbón que por más de 100 años alimentó principalmente las calderas del ferrocarril, los navíos y las fundiciones de todo el país; y el cobre, que desde su nacionalización en
1971 ha sido pilar del Producto Interno Bruto. Todos estos minerales dieron origen a la figura mítica del "oro blanco", el "oro negro" y "el sueldo de Chile", adjetivaciones que hablan del peso estratégico que han tenido en la imagen y conformación económica del país desde el siglo XIX hasta nuestros días, ya que son -en sus momentos de esplendor y cicloslas fuentes de riquezas básicas.

A partir de los recursos generados por esta actividad productora se han construido importantes obras públicas e infraestructuras diseminadas a lo largo del país. Todo el territorio y todas las ciudades de Chile, unas más unas menos, han sido parte de las bondades de esta riqueza, lo que espacialmente

1 Escuela de Diseño de la Facultad de Arquitectura de la Universidad de Valparaíso, Valparaíso, Chile. juancarlosrodriguezt@yahoo.com

2 Escuela de Arte de la Facultad de Artes de la Pontificia Universidad Católica de Chile, Santiago, Chile. pmirandb@uc.cl

3 Escuela de Psicología de la Facultad de Filosofía y Educación de la Pontificia Universidad Católica de Valparaíso, Valparaíso, Chile.pmedinahernandez@yahoo.es 
ha dejado huellas materiales y simbólicas que constituyen aspectos de la memoria y los imaginarios que han ampliado el mito de la grandeza minera.

Así, hacia 1930

Chile ya no es sólo paisaje, rincones o loca geografía, sino una superficie humana donde se debaten proyectos colectivos en plena evolución /.../ Las faenas mineras principalmente imprimen a la naturaleza un ciclo que va desde un antes no siempre histórico -cuando no heroico- hasta un presente históricamente situado donde los individuos adquieren su identidad a partir de la acción normativa que rige el trabajo y el mercado (Barraza et al. 1992:9).

En las ciudades mineras, los hombres primero y después las familias, se han apropiado -en virtud de la estabilidad de las condiciones laborales y de la dualidad techo y trabajo- de un espacio para elaborar los proyectos vitales y desde ahí generar arraigo local, así como una identificación con un entorno ambiental y social específico dado por formas rituales altamente formalizadas en consonancia y complemento con el tiempo industrial, en una relación lógica y normada entre los espacios públicos, laborales y domésticos.

El tiempo industrial constituye un rasgo central en el marco del desarrollo de la actividad minera, pues se constituyó tempranamente en una forma de disciplinamiento y posterior dependencia de las poblaciones de baja y nula escolaridad venidas de zonas rurales (e inclusive de otros países, como es el caso del salitre y el cobre en el Norte Grande) a trabajar en las faenas. Este tiempo industrial se hace acompañar de un tiempo social y cultural regulado y ritualizado, se da en un espacio social segregado y delimitado geográficamente y permite, en tanto forma de control, la visualización y contención interior de los miembros de las comunidades. A la vez funda las bases de un modo de ser colectivo muy estable en sus claves y simbolismos en las ciudades, fuertemente autorreferencial, dependiente y paternalista respecto del empleador ${ }^{2}$ y que potencia, de manera intensa, elementos de adscripción y filiación como rasgos de distinción y constitución de las identidades.

Este modo de ser cotidiano, ritual y sincronizado que se da en la sociabilidad de los enclaves mineros, corre en paralelo con la forja de un conocimiento experto, un saber hacer especializado que marcará las vidas de generaciones a través de su aprendizaje, incorporando al mundo del trabajo a los más jóvenes, prefigurando en gran medida el derrotero de sus vidas. Así, el proyecto vital, que es el proyecto de producción de la vida, que corresponde "a la fuerza por la cual el presente arma una relación con el futuro y no con el pasado" (Sarlo 2005:11), manifiesta que, con el correr del tiempo, no serán los individuos los que se afilien al mundo minero, sino familias completas, las cuales se transforman en familias mineras del carbón, el salitre o el cobre y que viven en las ciudades-campamentos construidas en sus singularidades para ser eficientes y complementarias al objetivo de la empresa, a la generación de riqueza. Por tanto, tenemos cuerpos y voces que configuran una comunidad de trabajadores de los distintos minerales las que, ligadas a organizaciones, muestran el real valor de ellas y de la noción de trabajo que atraviesa la relación del espacio público y privado, pero por sobre todo en este tipo de culturas del trabajo, permite visualizarla con gran nitidez en las dimensiones de lo "ideológico, lo organizativo y la articulación social" (Cardoso de Oliveira 2007), es decir, la identidad, el grupo y las relaciones.

La dinámica interior de los centros mineros se encuentra asociada, por una parte, a la realización de objetivos definidos como colectivos por la Compañía y, por otra, a la existencia de una esfera de acción colectiva de los mineros, situación que define la condición, a veces ambigua, de campamento, ciudad y vida económica. Esta imagen no estaría completa si, desde la antropología, no visualizáramos el realce que tiene el territorio o la figura de lo territorial como marco para la acción y la realización, ya que como sostiene EvansPritchard (1997), las relaciones de producción se dan dentro de los límites de un sistema territorial, en extensiones definidas y respecto de las cuales existe conciencia de que tal condición marca la identidad y ofrece una condición de exclusividad al encontrarse al interior. En el caso del campamento y de la ciudad minera, los límites de la comunidad están dados por las demarcaciones físicas de los volúmenes de la arquitectura, los espacios públicos y privados, los servicios y los modos normativos establecidos por la Compañía. El campamento posee una estructura básica y funcional sólo ligada a objetivos productivos. Se concibe sólo como lugar de trabajo, por lo que 
no está pensado para proyectos de vida de tipo familiar, estable y permanente, prescindiendo de servicios e institucionalidad compleja como hospitales, escuelas y comercio independiente. La ciudad minera está pensada como un sistema total para un habitar que trasciende lo meramente laboral, incorporando dimensiones recreativas, religiosas, sociales, habitacionales, educativas y sanitarias, que en su concepción integrada permiten proyectarse más allá de la fuente de trabajo.

\section{Las Ciudades Mineras}

La impronta más elocuente de este proceso de constitución y configuración urbana se encuentra en la zona sur del país, donde la explotación submarina del carbón consolidó a partir del siglo XIX a Lota como la primera ciudad industrial. En ésta, que hoy cuenta con unos 50.000 habitantes, pueden apreciarse todos los atributos conferidos a la revolución industrial. Allí se desarrolla, tempranamente, la organización más fuerte que haya podido desarrollar el capital chileno en torno al trabajo y es en este enclave productivo donde se impone la salarización, el trabajo infantil, la temprana inserción de los jóvenes al mundo laboral, la maquinización, el trabajo en serie, educación y sometimiento de los trabajadores indígenas y campesinos reclutados e integrados a una cultura horaria cronológica propia del rigor de la industrialización. Es ahí donde surge también la pobreza urbana como un modo de vida, la que ha sido ampliamente documentada en el trabajo de Di Tella et al. (1966).

De este proceso de reclutamiento se desprende que, al igual que las salitreras y en la minería del cobre, las diferencias sociales entre los distintos grupos que coparticipan en los procesos productivos son muy marcadas. Esto da cuenta de que existe estructuralmente un repertorio específico y limitado de roles posibles de desempeñar y alcanzar en términos de movilidad social, que contiene ciertos códigos lingüísticos propios y que son éstos los que permiten una identificación que favorece el reconocimiento como miembros de un modo de trabajo o subcultura, en el que se distinguen prestigios, jerarquías, competencias, calificaciones y experiencias (Rodríguez y Miranda 2010, 2008, 2005). En Lota, la tendencia a institucionalizar las diferencias sociales es muy clara, existiendo una escuela de la Compañía reservada sólo para niños de empleados y otra para hijos de obreros.
En perspectiva, con el correr del tiempo se configuró una rígida cultura del trabajo y una cultura del carbón que se extendió más allá de las labores propias de la mina y de los límites de la ciudad. Surge un sujeto particular con identidad lingüística, laboral y de clase, organizado y proactivo, anclado en una actividad única que se realiza en la profundidad de la tierra submarina; allí, la actividad minera es tan riesgosa y distinta, que es considerada por muchos estudiosos como titánica, heroica y fabulosa (Corvalán 1992:129), la que en su dependencia ha generado unas relaciones laborales que podrían calificarse de tipo semifeudales por la sujeción del minero y sus familias al empleador en lo alimenticio, la propiedad de la vivienda, la calefacción del hogar, el control del tiempo y la inamovilidad del trabajador.

Las minas, como lugar antropológico, configuran un espacio cartográfico específico donde el trabajo constituye, por excelencia, la singularidad dominante y paradigmática que identifica a estas comunidades. Las familias y la socialización a través de generaciones se vuelven tributarias de este modo de trabajo, por lo que se constituyen comunidades de trabajo. La mina, como centro neurálgico, será también la que abre y cierra el mundo de las oportunidades, estableciendo unos confines físicos muy inmediatos, la que especifica los roles de género e invisibiliza a las mujeres, la que marca al territorio y a sus hombres, por lo que es desde ahí, junto con la seguridad que ofrece el campamento o la ciudad adyacente, donde se configuran los proyectos de vida y se instauran las certezas básicas y las culturas en sus rasgos diferenciales como especificidad minera.

En estos contextos mineros, la identidad está potenciada, principalmente, debido a que las compañías mineras tienen un gran dominio sobre el conjunto de la vida social, esto ocurre ya que las organizaciones son ordenadas, estabilizadas y reguladas a través de reglamentos, así como también son contenidas para evitar aspectos anómicos o disfuncionales a los objetivos particulares de ella. De esta manera, la compañía provee la vivienda, la alimentación, la recreación y el trabajo, siguiendo así con el control y la segregación de los espacios de interacción de acuerdo a los estatus, diseñando un mundo profesional cerrado, el cual va de la mano del pleno empleo, como en el caso de los enclaves del cobre y el salitre, que prefiguran una rutina, una estructura, una proyección, un futuro, todo lo cual constituye en última instancia, el único mundo 
posible para varias generaciones que están dentro de las ciudades o campamentos. De esta manera, existe un doble vínculo, ya que toda la respuesta organizativa que desde el nivel sindical promueve demandas hacia el empleador no sólo se refieren a cuestiones relativas a lo propiamente laboral, las remuneraciones o las condiciones de trabajo y seguridad, sino que además lo son siempre en relación a la ciudad o tienen impacto sobre ella, demostrando la importancia asignada a ésta por quienes viven allí.

En su conjunto, las ciudades del salitre como María Elena y Pedro de Valdivia, las del cobre como Sewell, Chuquicamata, Potrerillos y El Salvador (véase Garcés 1999, 2007) y Lota, la del carbón, revelan un arte de imaginar y hacer ciudad por parte de las empresas propietarias de los complejos urbanos industriales, que en lo arquitectónico -que es un elemento diferencial de las ciudades y que las transforma en únicas- hace mirar a sus habitantes hacia su interior para acrisolar así una relación doble, en el trabajo y fuera de él, generando un diseño que permite establecer un lazo emocionalmente seguro para sus habitantes, lo que activa con el paso del tiempo la creación de universos culturales de gran fuerza e importante identificación. Esto es parte consecuente de un plan condicionado por las necesidades de la monoindustria, el cual unifica la imagen de la ciudad dentro de sus matices, apropiaciones, segmentaciones y subjetividades; sin embargo, esto también cuestiona la idea misma de ciudad, en la medida que lo que define a la ciudad es la libre circulación de hombres y mujeres. Claramente, respecto a las ciudades aludidas no estamos frente a ello, ya que la superestructura económica moldea la sociabilidad, las vidas y las posibilidades de desplazamiento en su interior.

En su forma de Company Town, Industrial Village o Cité Ouvrière, las cuales son ciudades que giran en torno a una actividad central, con todas sus divisiones funcionales (instalaciones industriales, habitaciones y servicios para la vida cotidiana), advienen en un territorio que decanta como perteneciente al reino mental del habitante promovido por la empresa; un modelo para ejercer autoridad y autocontención, un modelo de entender la entretención y la convivencia para delinear y proyectar la vida, en el cual puede observarse el ciclo vital desde la edad preproductiva a la postproductiva, que tiene profundos impactos sociales, económicos y territoriales como es el caso del desarrollo de la vivienda obrera. En estas claves descansa una intensa sociabilidad que se construye entre iguales diferenciados, definida por lo que se conoce como "rol", el cual identifica una categoría administrativa que diferencia a los miembros de la empresa por jerarquía, distribución del trabajo y por la posición socioespacial y jerarquizada en función del rol específico que se ocupa ${ }^{3}$.

En estos espacios comprimidos donde se nace, crece y vive, se marca el horizonte de la vida; es donde circula la palabra, donde se expresa lo relacional, lo dialógico, lo conversacional, porque es parte de un ámbito de semejanzas que da paso a la "comunidad imaginada" (Anderson 2002) del carbón, el cobre y el salitre, que puede ser narrada inclusive más allá de la existencia de las mismas. Un imaginario colectivo, lo que en términos de Cornelius Castoriadis (1981) ofrece la singularidad de lo propio que marca los cambios y transiciones $y$, por sobre todo, manifiesta un imaginario que orienta y dirige la vida social por generaciones. También se da allí la relación con las materialidades en sus usos, así como en sus referencias que marcan las actividades diarias para regular el tiempo, que dibujan las ciudades y campamentos en la memoria ${ }^{4}$. En la densidad de sus redes, concibiendo estos espacios como mapas mentales, aparecen las seguridades básicas, las estructuras cognitivas y sociocognitivas que se dan en los individuos y grupos para hacerse cargo del lugar, del territorio, la naturaleza, el país y el mundo. En el registro de los espacios que son auténticos marcadores de sus prácticas y rasgos de diferenciación pueden apreciarse la valoración etnográfica de elementos históricos, culturales, organizativos, recreacionales y estéticos que permiten mirar la vida de determinada forma, porque ahí, en términos de memoria larga, se experimentan y narran los universos de la muerte, la enfermedad, la fatalidad, los triunfos deportivos, las derrotas, la huelga, la conquista social, los grandes y pequeños eventos, que ponen de manifiesto un continuum significativo e interpretable de la experiencia en el tiempo de los trabajadores y sus familias.

Entonces, si en la narración de la experiencia de lo que ha sido el ciclo de vida de trabajadores y habitantes fluyen los sentimientos cotidianos en sus asociaciones a la compañía empleadora, podemos decir que son éstas las que construyen en gran medida el espacio minero de las relaciones y la comunicación, configurando las bases de lo que será la cultura minera urbana. Es la seguridad y paternidad de la organización, con todo lo que 
significa el uso restringido de los espacios, lo que se termina por imponer y valorar.

La empresa se manifestaba regalándoles a los niños que tenían las mejores notas un parcito de zapatos, esos zapatos se colocaban dos veces en el año... para las fiestas patrias y pascua y año nuevo... Después el mismo papá nos decía: "sácate los zapatos no más, para que te duren"... bien le duraban o quedaban chicos... como uno iba creciendo.... Pero por lo general uno también se acostumbraba al clima, a andar descalzo... y con pantaloncito corto... Tú veías en la calle a todos los niños jugando a la pelota, a la escondida... y todos descalzos. Entonces nuestra vida fue de niño... dura ${ }^{5}$.

Etnográfica y etnológicamente en el caso de Lota, la puesta en marcha de la actividad carbonífera a partir del siglo XIX impone, por una parte, la necesidad de resolver cuestiones de orden técnica, tales como: la fortificación, la ventilación y el desagüe de las galerías para una explotación eficiente y de menor riesgo; y, por otra, conjugar ese mundo íntimo, obscuro, subterráneo, que arranca de las entrañas de la tierra y del mar, con la vida de la superficie: la de la lluvia, el sol, la luz; del día a día donde se vive el sino de la reproducción social y biológica. En este intento permanente de armonización entre el desarrollo económico y rentabilidad del complejo industrial y la vida diaria de las personas es donde debe fijarse la mirada de perspectiva si quiere entenderse el movimiento sindical, el devenir infausto de la ciudad y la pobreza material de sus gentes, así como las estructuras que contienen las vidas (véase Di Tella et al. 1966).

En medio de toda esta contradicción surge un tipo de trabajadores especializados y dependientes de una organización, que en una nomenclatura clásica serían los primeros proletarios en cuanto asalariados y con ella sobreviene -como ha ocurrido en tantas partes- la pobreza urbana dentro de sus márgenes.

...no había agua en las casas tampoco. Entonces los niños que eran más grandes acarreaban agua en baldes, del pilón. La mamá cuando llegaba el papá del trabajo, que llegaba todo teñido en carbón, echaba a todos los niños para afuera y ahí la mamá 'trapeaba' al papá, con un lavatorio lo lavaba. Porque no teníamos baño tampoco... de tal manera que aquí... muchos no quieren decir la verdad... y yo la digo.... en nuestras casas había chinches, pulgas, piojos, ratones, ¡cucarachas!... Porque era antihigiénico todo esto, los basurales... Entonces la mayoría de los niños sufrían de sarna ${ }^{6}$.

Por tanto, la vida reposa sobre la actividad monoproductora, la especialización y dependencia de sus gentes. Desde la segunda mitad del siglo XIX se constituye el proyecto de vida, se visualiza en específico el ciclo de vida de hombres y mujeres, el cual revelará la vulnerabilidad del modelo de gestión integrado urbano-industrial a partir del cambio de la matriz energética en la década del 50 del siglo pasado, cuando se introduce el petróleo y las fuentes hidroeléctricas para producir energía.

Lo importante aquí es que el trabajo en el salitre, en el carbón y en el cobre o, dicho espacialmente, en el desierto más árido del mundo, recorriendo kilómetros bajo el mar o penetrando la cordillera, dan origen a culturas del trabajo (como referencia común) que configuran adscripciones en la estructura social, es decir, una posición social y de clase, un rasgo de identidad como "cualidad relacional" (Archuf 2002), dada por la explotación de un recurso único. De modo que una caracterización antropológica y sociológica implica el reconocimiento de un sector de trabajadores en cuanto obreros y la filiación asociada a la explotación de un recurso en un entorno geográfico, ambiental y urbano específico. Así, por ejemplo, tratándose de trabajadores u obreros ligados la explotación del nitrato en el Desierto de Atacama, la filiación y autodefinición corresponde a la de "pampinos", la que será extensiva a toda la unidad familiar y a todo aquel que nació ahí o a aquel que terminó por avecindarse después de una larga permanencia.

\section{Crisis, Ciclos y Nuevos Imaginarios}

Tomando como referencia etnográfica a Lota a manera de ciudad del carbón y comunidad carbonífera, podemos plantear que por distintas causas todas las comunidades especializadas, a las cuales, se adscriben las faenas mineras y las formas de vida construidas y consolidadas durante generaciones en ellas, han entrado en crisis global y sistémica, la que avalada por la dependencia de 
grandes organizaciones está asociada a los ciclos de vida de la explotación del mineral, a la ley y valor de éste, al cuestionamiento de sus formas de trabajo originarias y sus desarrollos tecnológicos. Esto revela que las vidas de las gentes, las culturas del trabajo, los modos de ser y hacer, la existencia de las mismas ciudades o campamentos dependen de factores externos a su propia dinámica e interés y que esta condición especializada no hace más que revelar que la vida y el habitar en ellas implica -profesional y familiarmente- siempre una posición de cierta vulnerabilidad dentro de los marcos de una economía internacionalizada o globalizada, la cual fija, desde los centros de poder, el valor del mineral e impone los niveles de demanda.

La idea de los ciclos de vida mineros corresponde a que podemos encontrar distintos momentos en la explotación del carbón, el nitrato o el cobre. La introducción o aparición en el mercado del recurso; su crecimiento en relación a la demanda; su madurez dada por los límites de crecimiento de los mercados, con ciertas muestras de estancamiento; la aparición de la competencia interna; y la declinación, en la medida que el producto se convierte en obsoleto al ser reemplazado por otro o las ganancias se vuelven bajas o negativas u otros competidores toman el mercado ${ }^{7}$. Estos ciclos pueden ser largos o pequeños, definitivos o transitorios, pueden hacer sucumbir o recuperarse a la cultura del trabajo y la comunidad, pero al estar ligados a la vida colectiva que gira en torno a la actividad, siempre son más que cuestiones propiamente económicas las que se juegan. En su desarrollo, el ciclo minero con su mayor o menor severidad y extensión, por sobre todo afecta a las familias desestabilizando sus proyectos y arraigos, así como el valor y reconocimiento que tienen los roles históricamente desempeñados.

El ciclo de la industria del carbón, por ejemplo, entra en un proceso de declinación a mediados siglo pasado -tal como se ha dicho- cuando la matriz energética del país deja de lado su uso y comienza la expansión del consumo de petróleo y de la energía hidroeléctrica. En el caso de la explotación del nitrato, donde el salitre fue importantísimo no sólo como fertilizante para la agricultura sino para la elaboración de explosivos y la guerra, su descenso coincide en la década del 1920 con la introducción del salitre sintético por parte de Alemania. A esto se suma el bajo desarrollo tecnológico de las empresas que obligaba a que el trabajo de los hombres fuera esencialmente físico, donde los gastos más altos asociados a la explotación fueron mantener un contingente muy importante de mulas y forraje, más el combustible para hacer hervir los caldos. Por tanto, con poca tecnología y poca mecanización en un lugar de alto stress ambiental, sólo se podía trabajar con caliche de alta ley, lo que convertía a la industria en muy poco eficiente. En el caso del cobre, la producción es oscilante ya que la explotación está mediada por la demanda internacional. Ejemplo de ello es lo que ocurrió en la década de 1990, donde la libra de cobre alcanzó precios muy deprimidos y todas las pequeñas empresas debieron cerrar sus operaciones ya que sus costos de producción eran significativamente más altos que el valor comercial, lo mismo que obligó a los trabajadores autónomos a terminar sus actividades extractivas, como ocurre en el caso de Taltal (Figura 1).

\section{EVOLUCIÓN DEL PRECIO DEL COBRE \\ (centavos de US\$ por libra)}

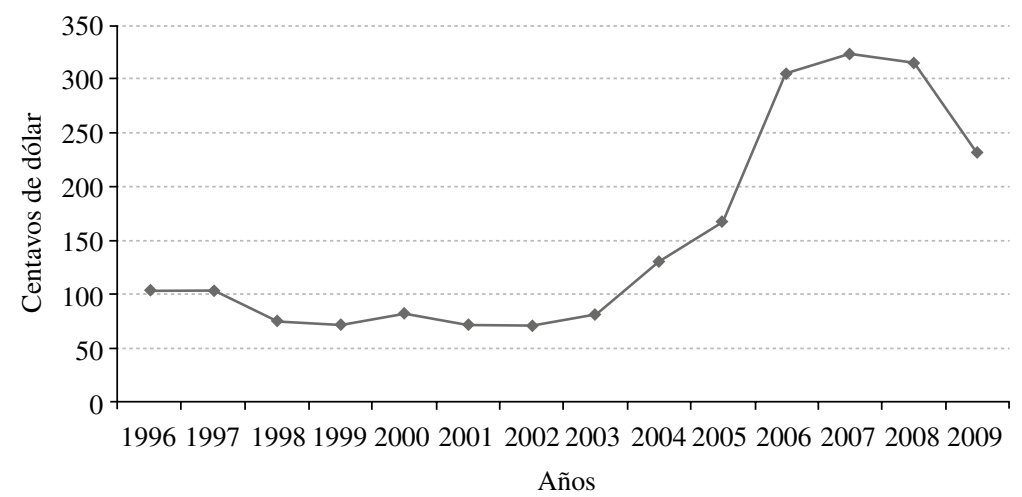

Figura 1. Gráfico de Valor Internacional del cobre. Elaboración de los autores.

International copper price. Chart produced by the authors. 
Es tal el impacto que tienen los factores externos en las ciudades y culturas del trabajo, que en Taltal, un antiguo puerto minero salitrero que data del siglo XIX y cuya población actual depende en la totalidad del trabajo de explotación de pequeños y medianos yacimientos de cobre (ocho a diez trabajadores por unidad productiva), que en pocos años y producto del bajo precio internacional del metal, disminuyó su población de unos 15.000 a algo más de 6.000 habitantes. La actividad monoproductora no dejó márgenes para que la población pudiese reconvertirse a otra actividad, por lo que más de 700 personas se transformaron en empleados municipales subsidiados por el Estado, siendo que la plantilla institucional normal no supera las 35 personas. Taltal, dentro de su particularismo ambiental y geográfico, conjuga desierto y mar; siendo el mar un elemento de frontera, desconocido e infranqueable simbólicamente para los mineros, esto, a pesar de que pudiese ser un elemento alternativo que genere un "nuevo proceso de reconversión", lo cual queda impedido ya que corresponde a otra tradición y cultura del trabajo (Figura 2).

El ejemplo es importante en la medida que-desde el siglo XIX- este puerto salitrero estaba asociado a una red ferroviaria y a un cantón de oficinas de explotación de nitrato que llegó a concentrar unas 30.000 almas. En pleno Desierto de Atacama, tuvo plantas de desalinización de aguas, un hipódromo, sistemas de taxis, suscripciones a los más importantes periódicos del mundo, bancos, casas de estiba, salones de eventos. Sin embargo, el cierre de cada una de las "oficinas" de explotación de nitrato por su nula o baja rentabilidad, su posterior abandono y destrucción, extinguieron una forma de apropiación del espacio y una cultura del trabajo. Con ello, los que quedaron en la ciudad -la que hacía de centro neurálgico- tuvieron que reiniciar el aprendizaje de un nuevo rol: pasar del trabajo a pampa desnuda de la explotación del nitrato al trabajo de la explotación en piques de vetas de cobre y plata.

Lo interesante aquí es que se enfrenta, como parte del ciclo de la actividad minera, una declinación definitiva de lo que fue la explotación del nitrato con la figura de organizaciones empresariales y una redefinición de sí mismos en cuanto comienza a ser explotado principalmente el cobre, que constituye un rol distinto, en la medida que el primero se realiza en superficie y el segundo en actividades subterráneas. Sin embargo, esta relación con el

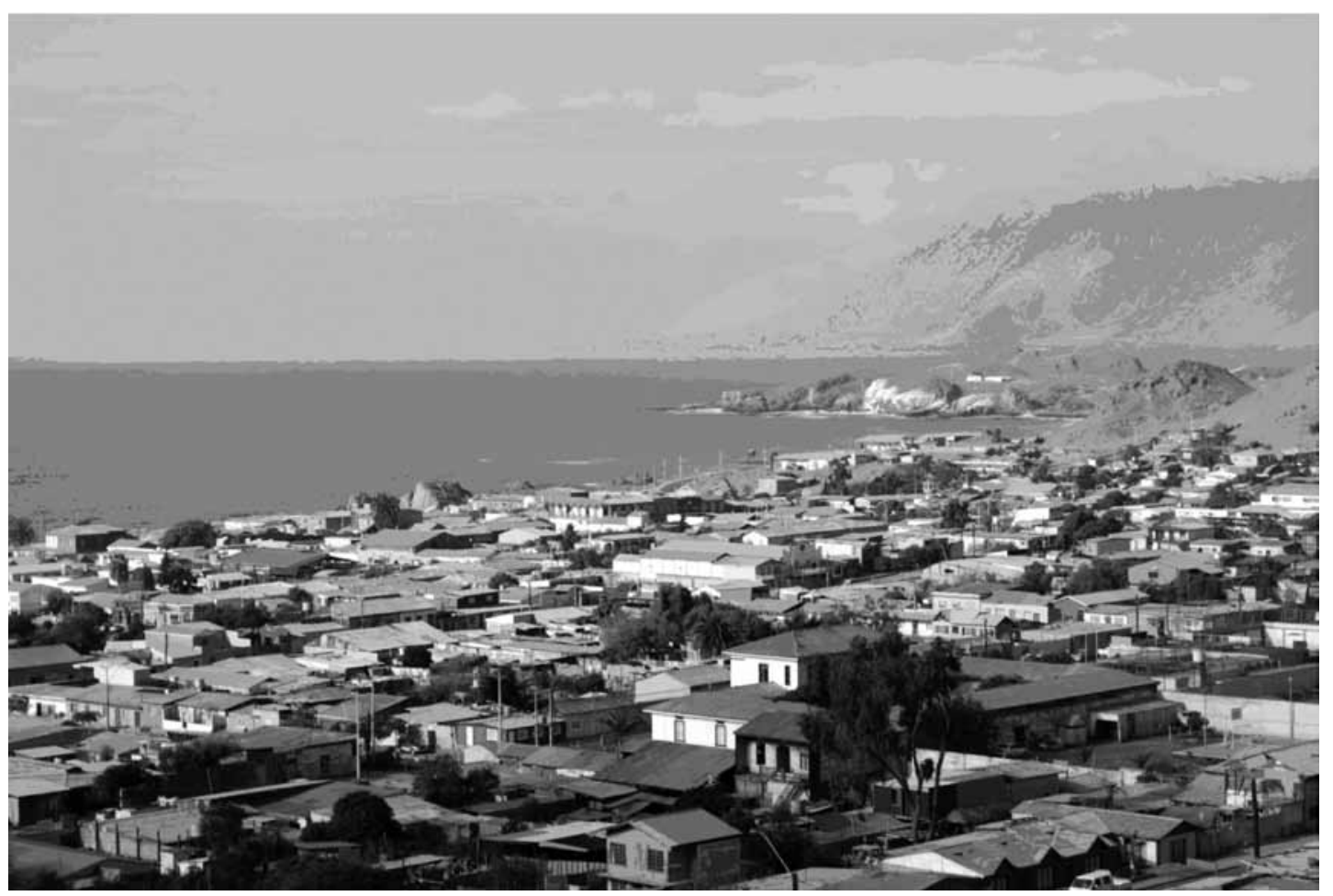

Figura 2. Vista de la ciudad de Taltal. Registro de los autores.

View of the city of Taltal. From the records in possession by the authors. 
nuevo objeto de trabajo indica que la sostenibilidad y sustentabilidad de la pequeña explotación dependen de factores que no son controlables por la comunidad. Así, la evidente vulnerabilidad, ya que no pueden controlar el precio internacional del cobre, hace que la población residente sea necesariamente oscilante y que el sentido de pertenencia e identificación con la ciudad se vea severamente alterado, en la medida en que no puede esperarse una continuidad de roles porque las expectativas de los más jóvenes son más urbanas (o metropolitanas) y urgentes, aunque ligadas al mundo minero de las grandes compañías; asimismo, su sentido temporal es distinto del tiempo del mito que está en la nobleza y glamour de la arquitectura taltalina, el ferrocarril y los antiguos muelles que se ubican en la retina de los mayores.

Sin duda, lo que sostiene al imaginario minero de Taltal es que el cobre mantiene vigencia y relevancia creciente como materia prima a diferencia del carbón, lo que les ha permitido sobreponerse al fin del ferrocarril y de la actividad portuaria, a que Lan Chile en los 60 dejara de volar y que la Carretera 5 Norte no se construyera pasando por la ciudad como era el clamor de vecinos y autoridades. Pero también porque existe un paradigma liberal; los mineros taltalinos son emprendedores porque el esfuerzo, más "un golpe de suerte", puede transformarlos en hombres de riqueza, como ha ocurrido muchas veces en el pasado, reafirmando la imagen de El Dorado. La deficiente infraestrucura y la poca actividad cultural de la ciudad no reflejan el dinero circulante, aunque en el ciclo expansivo genera campamentos satélites de inmigrantes vinculados a la explotación cuprífera. Los mineros tienen un concepto distinto de trabajo y de movilidad; son high tech, son modernos y tecnológicos, invierten en vehículos último modelo, maquinarias, herramientas, baños químicos, generadores eléctricos, calentadores de agua solar, GPS; buscan oportunidades y recorren para construírselas. Por eso, en etapas de buen precio del cobre como ocurre en el presente, la ciudad recibe inmigrantes que presionan por un lugar estable, para que les construyan viviendas y les habiliten instalaciones de agua y de electricidad, a diferencia de Lota que envejece, pierde población -30.000 habitantes en un par de décadas-, no hay inversiones y no se encuentran emprendimientos.

En el caso de Sewell, asociada a la explotación del cobre y enclavada en un desnivel de la Cordillera de los Andes a $2.140 \mathrm{msm}$, su poblamiento comienza en 1904. La ciudad es conocida como "la ciudad de las escaleras", ya que no cuenta con calles sino con edificios a los que se accede a través de éstas. Como en todas las ciudades mineras con características de Company Town contó con piscinas temperadas, cine, escuelas, salones de eventos, hospital e iglesia; todos servicios segregados que fueron utilizados por los 15.000 habitantes que llegaron a vivir en 1960, momento de mayor densidad demográfica (Figura 3).

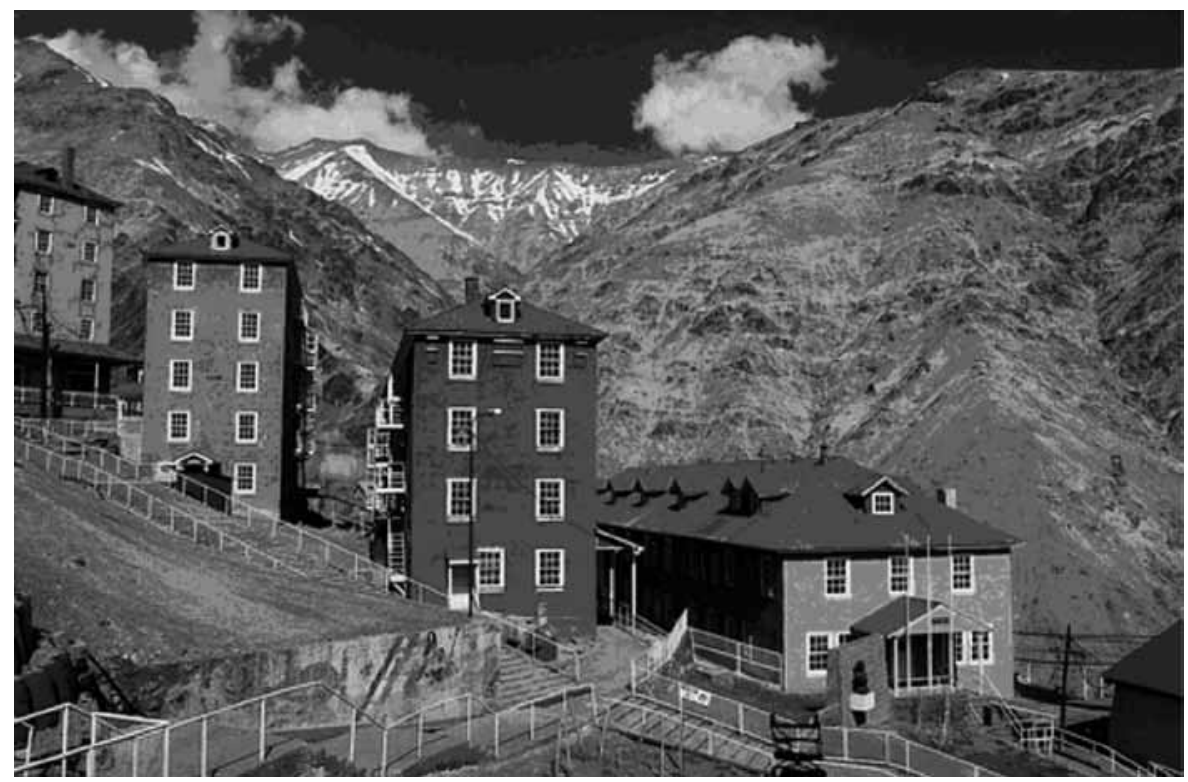

Figura 3. Vista parcial del complejo habitacional Sewell.

Partial view of the Sewell housing complex. 
Sin embargo, entre la chilenización y la nacionalización $^{8}$ de las riquezas, 1968 a 1971, comienza el traslado de sus habitantes a Rancagua, una ciudad distante a 53 kilómetros. Las causas de este proceso de despoblamiento que concluye con su cierre definitivo y que en gran parte condujo al desmantelamiento de parte de la ciudad, están asociadas al alto costo que significaba la mantención de la misma y a los subsidios directos e indirectos a personas no ligadas a trabajos productivos. Pero es con la decisión del cierre que se pone fin a casi 70 años de vida en común; se rompe y desarticula el tejido social, se dispersa la sociabilidad, se altera la socialización tradicional y se modifica el proyecto vital ligado al mundo cordillerano de interacción en las escaleras y de encuentro común. Entonces, en lo específico, si lo que define a lo minero histórico es la condición de sociabilidad dual, dentro y fuera del trabajo y ésta ya no va más, de manera violenta, se pone fin a esa cultura del trabajo. De modo que, aunque la actividad permanezca, el daño es inevitable y produce una dispersión irrecuperable de la memoria, obligando a las personas a reordenar sus vidas en nuevos lugares.

Chuquicamata, ciudad ligada a la mina del mismo nombre y que inicia la explotación de cobre en 1915, constituye la ciudad minera más importante y emblemática del Desierto de Atacama en el que habitaron trabajadores y sus familias. Dos factores terminaron con la urbe y su sociabilidad en el año 2007: primero, en 1992 se le define como un área saturada de material particulado respirable, anhídrido sulfúrico y también por sus altos índices de arsénico y, segundo, la necesidad de expandir las faenas hacia el territorio ocupado por la ciudad.

En un largo proceso que tomó más de una década, las faenas avanzaron sobre la ciudad, hasta que se hizo imposible mantener a la población que tenía sus casas en comodato, dando paso a un proceso de erradicación y de demolición de las viviendas y de la infraestructura. Se va el Regimiento $\mathrm{N}^{\circ} 1$ de Chuquicamata, se cierra su Hospital Roy H. Glover en el año 2001, se pone fin al comercio y se trasladan las escuelas. Este camino forzado y no expedito, resistido y doloroso, no hace más que revelar cómo el capital se ubica más allá de los sentimientos de pertenencia y arraigo que las personas desarrollan, de los lugares de referencia, de las sociabilidades, de los sentimientos comunes y memorias, de las historias (Figura 4).

La población, so pretexto de una situación inevitable y de una mejor expectativa de vida, fue

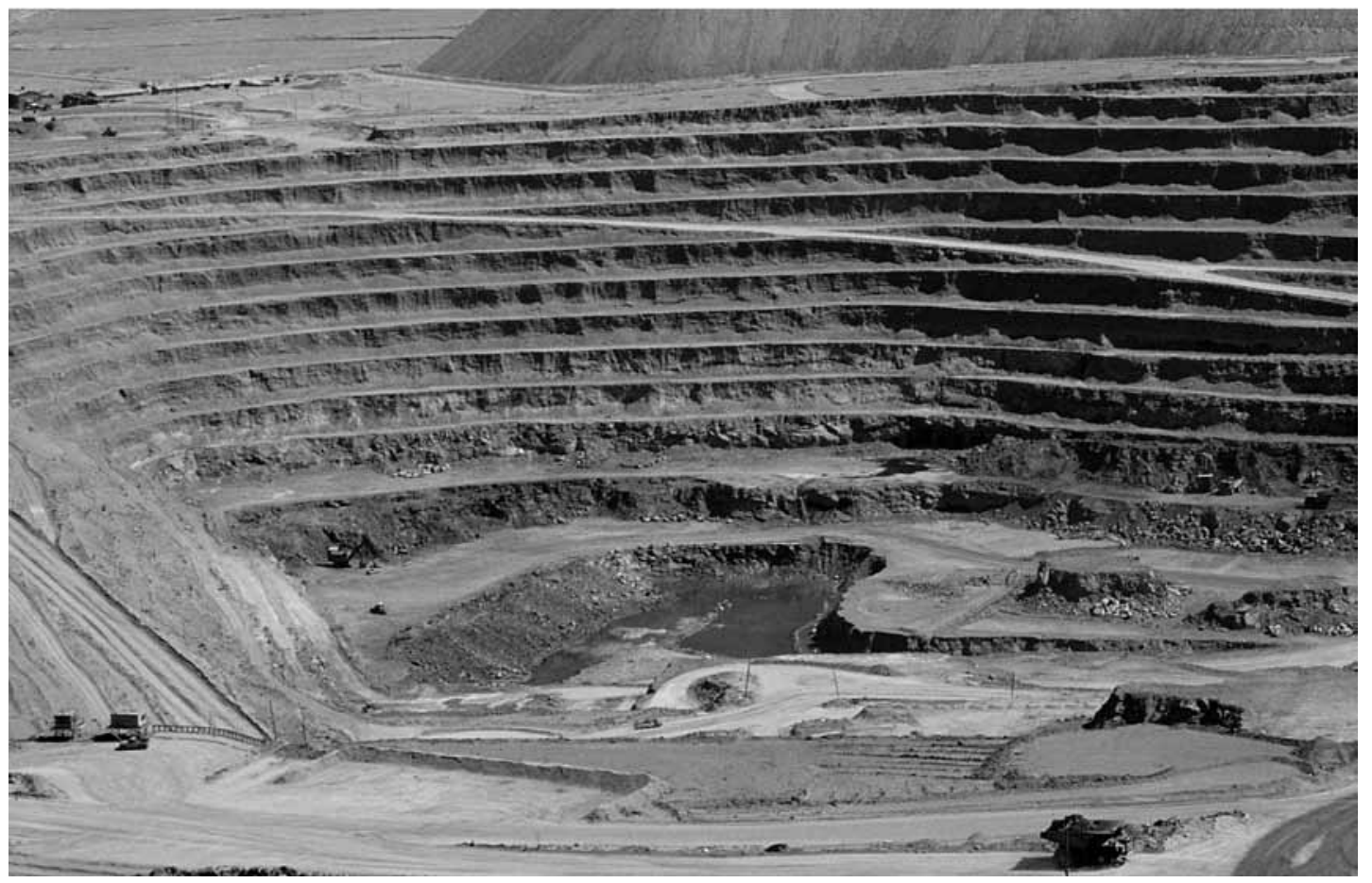

Figura 4. Mina de Chuquicamata.

Chuquicamata mine. 
relocalizada en Calama, ciudad adyacente y considerada siempre "secundaria" para sus habitantes históricos, que siempre constituyó su alter ego degradado e inferiorizado. Aquí, en un intento por restablecer lo perdido, destruido y siniestrado, la salida fue la creación de una nueva ciudad para los erradicados: la "Nueva Calama". A varios años del doloroso proceso de erradicación, las quejas se oyen por doquier, no sólo por lo nuevo sino por lo perdido, y atrás, sólo como recuerdos, quedan los clubes exclusivos, el teatro, los almacenes y las viviendas históricas con las que se convivió por décadas.

Unas 30.000 personas participaron en una festividad de cierre. Los fuegos de artificio se hicieron sentir entre el 31 de agosto y el 1 de julio de 2007, para despedir a la ciudad fantasmagórica. En el 2008 a la ciudad de Chuquicamata se le declara oficialmente como "zona industrial", autorización suficiente para que no quede vestigio de 92 años de sociabilidad y de proyectos vitales.

También sucumbió Pedro de Valdivia (19311996), una ciudad del salitre concebida según la tradición utópica, es decir, pensada antes de ser construida. Una ordenanza de la empresa propietaria del complejo urbano en el que vivían más de 10.000 almas, decretó su cierre entre 1995 y 1996. La empresa facilitó camiones para el traslado de las familias a las ciudades adyacentes y cada día se iban apagando las luces de una y otra casa, de una cuadra y otra, hasta que la ciudad quedó en la obscuridad total, sin agua y sin servicios.

... el cierre fue también casi sorpresivo,... aunque habían comentarios previos de que iba a haber una reducción, vienen tiempos difíciles para la empresa, la empresa empieza a decir que el mercado está en contracción, hay dificultades, los competidores... nosotros ya sabíamos que venía un golpe crítico, habían rumores... entonces, se inauguró en Coya sur una nueva planta de yodo, importante, grande... entonces la jefatura de la empresa dijo ahí... que en un plazo de cuatro años se eliminará el campamento de Pedro de Valdivia, es decir la población, y quedará solamente como lugar de faenas... pero la familia se termina en Pedro de Valdivia en un plazo de cuatro años... y dos años después le corresponderá hacer lo mismo con María Elena... Dijo cuatro años, a los tres meses se dio la orden: se van todos porque aquí se terminó Pedro de Valdivia. Fue abrupto, la gente no hallaba qué hacer, como dijeron cuatro años, era suficiente tiempo para subsidio, arreglar e irnos, pero... muchos fueron traslados aquí a María Elena, pero la mayoría de los otros no... entonces fue sorpresivo y eso sí que fue dramático... tuvimos que ver los problemas que mucha gente tenía, eran nuestros amigos, todos éramos amigos en Pedro de Valdivia, todo el mundo... en la mañana salíamos y ipasábamos medio día saludando! sí, todos éramos conocidos, cuando no amigos éramos conocidos...eran apoderados de nuestra escuela... ${ }^{9}$

La ciudad quedó con sus vértebras al aire, saqueada, afásica. El cierre irreversible, feroz, violento, diseminó por todos los caminos a la subcultura de los trabajadores del salitre, pero en este caso, la determinación no sólo los dejó sin ciudad y sin vida cotidiana local, sino que los expulsó del desierto y de la tradición minera salitrera; es decir, quedaron como pampinos y pampinas fuera de la pampa.

María Elena, ciudad del salitre construida entre 1925-1926 con una cartografía también utópica, cuya propietaria es la empresa SQM, al igual que Pedro de Valdivia, hace años que se discute su condición de "ciudad". Cada día, la ciudad es menos ciudad, cada día es más campamento minero. La estrategia empleada para redefinir su funcionalidad es disminuyendo su número de habitantes a través de la implementación de una nueva filosofía del trabajo compuesta por la introducción del criterio de la flexibilidad funcional y numérica de la plantilla de trabajadores. Esto implica el fin del pleno empleo que justificó la fundación de la ciudad y la redefinición y rotación de roles entre los trabajadores de la Compañía o plurifuncionalidad a través de reasignaciones e incrementos o disminución de la plantilla a partir de la modalidad de subcontratación y de acuerdo a los valores y demandas internacionales de los productos derivados del nitrato (Figura 5).

Con tal filosofía, la ciudad se resiente por la incorporación de trabajadores foráneos y la emigración de habitantes históricos. Los subcontratados sólo vienen a trabajar, generan riqueza que se gasta en otras ciudades o regiones donde están sus familias, lo que deprime a todo el pequeño comercio, ya que estos trabajadores duermen y se alimentan al 


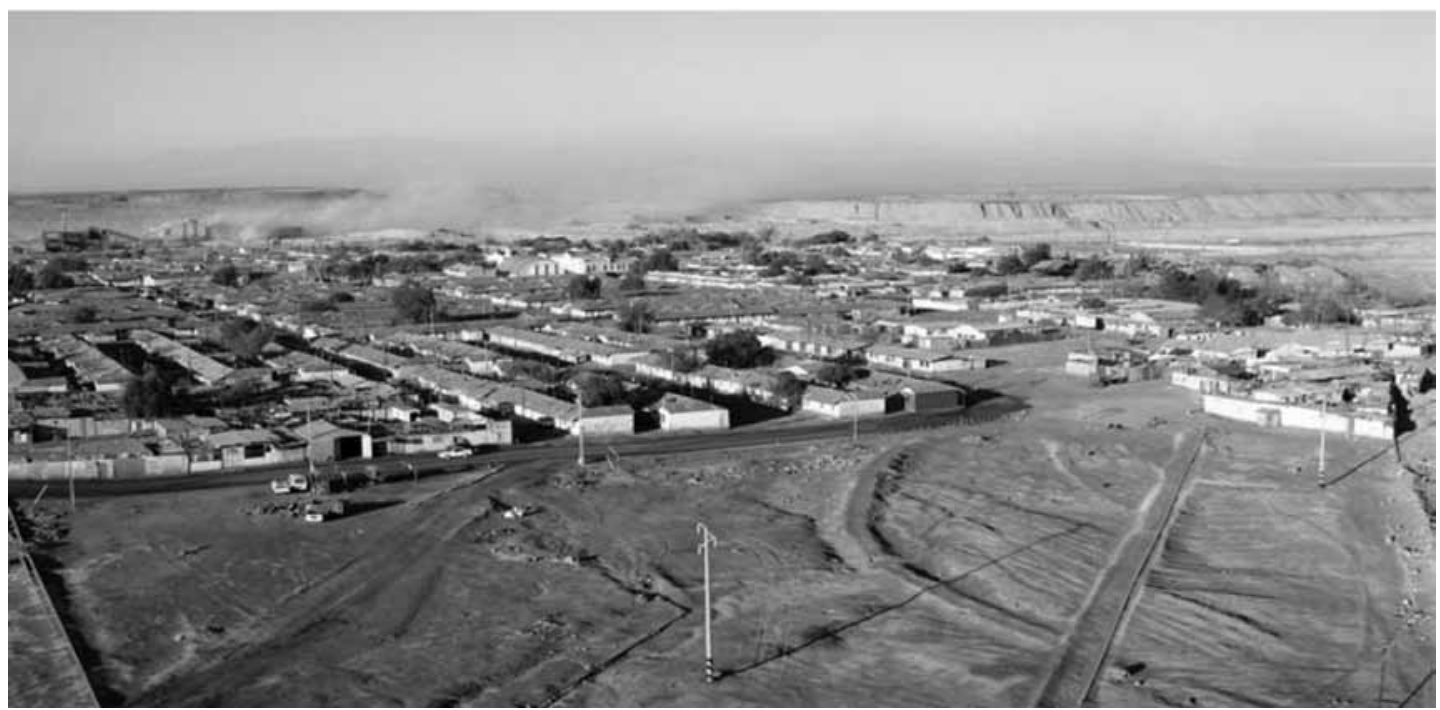

Figura 5. Vista de la ciudad de María Elena. Fotografía de Fernando Mandujano Bustamante.

View of the city of María Elena. Photograph by Fernando Mandujano Bustamante.

margen de la ciudad. A ello se suma una política de incentivos para que las familias la abandonen, con ofertas en dinero, ayuda para traslados, compras de viviendas en ciudades y regiones cercanas. En este caso, cada casa cerrada es una casa que no vuelve a ser habitada y es una familia menos. Una casa demanda agua, luz y servicios de mantenimiento que distrae recursos y personal de la Compañía, lo que no se encuentra en el horizonte de sus prioridades. Entonces, lo que era una ciudad se convierte en un paisaje de trabajadores solteros que mantienen una relación atópica con la ciudad; producen ahí, pero el imaginario de su proyecto de vida se encuentra en otro lado, porque sus familias y sus residencias están fuera de María Elena, ya que la condición de permanencia está asociada al trabajo en distintas modalidades de turnos. Se trata sólo de ir y venir por un número de días.

A partir de la implementación de distintos sistemas de turnos y subcontratación, del escaso dinero circulante y acrecentado por un importante sismo que derribó en el año 2007 gran parte del casco histórico de la ciudad, sus antiguos moradores van abandonando la ciudad del salitre conforme al empobrecimiento simbólico y material de la misma, ya que en ésta no hay inversiones, no se construyen casas con estándares modernos, ya no hay comercio que ofrezca servicios de calidad ni éste puede competir con la alimentación a escala otorgada a los trabajadores por parte de la Compañía. Así, todas aquellas cuestiones que le dieron vida y glamour -sus galas y bailes, su cine, teatro, Instituto Chileno Norteamericano de Cultura, los 25 deportes que se practicaban en pleno Desierto de Atacama- han desaparecido para siempre. La ciudad se queda sin masa crítica que la piense y sin espacios de constitución de ciudadanía. De los entre 9.000 y 10.000 habitantes históricos, hoy van quedando la mitad y con una proyección de que de aquí al año 2015 llegarán a una cifra inferior a 3.000.

¿Cuál es la señal después de 70 años?, ¿qué implica un cambio de formato de ciudad a campamento? Como ya se ha señalado, los campamentos no requieren a personas que no estén ligadas a las faenas: niños, ancianos y a muchas mujeres; en éstos se requieren sólo trabajadores con calificación definida y experta, éstos pueden provenir de cualquier rincón del país y desarrollar relaciones atópicas con el lugar de trabajo. La flexibilidad laboral, el know-how, el aceleramiento tecnológico, la automatización de los procesos, la irrupción de los medios de comunicación como promotores de lo deseable, la falta de mundo interno y el deterioro de la sociabilidad, más no el fin del recurso, es lo que pone fin a lo que históricamente -por generaciones-fue una socialización entrópica, con proyecto vital y una sociabilidad entre iguales y diferentes que consolidó un modo coherente de ver el mundo. Ese mundo cerrado se extingue y se vuelve poroso, ya que no ofrece ninguna posibilidad de desarrollar un proyecto para los más jóvenes como ocurrió en el pasado para muchas generaciones, por lo que se 
desarticula la comunicación interna sobre la base de la desconfianza y la ausencia de mirada colectiva tanto desde la familia como desde la comunidad.

En este caso, sus habitantes son los últimos pampinos. Todo después de ellos no será más que recuerdo y éstos desaparecerán como desaparecieron -hasta físicamente- más de 200 asentamientos salitreros a lo largo del Desierto de Atacama, los que se quedaron hasta sin nombre para ser nombrados.

...con las salitreras pasa algo que ha pasado con todas las civilizaciones de la tierra... al final ya no queda nadie que recuerde ya...llega un minuto que ya no queda nadie que recuerde ....entonces, poco a poco también, esa memoria heredada se va debilitando si tú no la escribes, o no la dejas guardada en un cuaderno, ¿cierto? Si no transformas esos relatos en letras se van a perder para siempre... si no estructuras gramaticalmente toda esa historia, eso se va a morir para siempre... cuando murió el último se murió todo ${ }^{10}$.

\section{Cultura y Desarrollo Minero}

Lo que hemos expuesto en relación a la vida de las personas y comunidades en el mundo minero urbano indica que las empresas son capaces de ayudar a sostener estos modos de vida que gestaron hasta que las rentabilidades sean las esperadas, lo que significa que las compañías pueden abandonar a la ciudad y romper el pacto con el que vive el día a día el trabajador y su familia. O, en otros casos, que los ciclos puedan estar en una fase de depresión y podrían revertirse en tiempos no muy extensos. Pero los casos más severos de ruptura con el mundo, construido y sostenido por décadas, se asocian al momento cuando la actividad extractiva se vuelve irreversible, como en el caso del carbón, el que energéticamente está en retirada producto de su huella contaminante. Es allí donde los trabajadores y el saber hacer entran en un pleito con la realidad, ya que acostumbrados a trabajar para una organización, les cuesta actualizar esta nueva experiencia; donde la vida de las personas, las culturas del trabajo y las ciudades deben reconvertirse, reinventarse o refundarse. En estos casos, como las huellas y heridas están en la ciudad, una de las estrategias de reposicionamiento es convertir lo que existencial y emotivamente fue una tragedia, en theme-parks históricos, o si se quiere derechamente en una museificación.

Desde el municipio hemos planteado como proyecto político la 'Refundación de Lota' a partir del patrimonio arquitectónico, cultural, histórico de nuestra comuna podemos sacar a la comuna adelante. Creando un polo de desarrollo, para ello le pedimos a la CORFO los terrenos, como sesenta hectáreas, las edificaciones de la ENACAR, el pique para construir un museo del carbón, del sindicalismo, con fines turísticos; proyectando un centro gastronómico en el muelle, queremos comprar los terrenos de Lota Green, que son como siete hectáreas, para trasformar a Lota como un centro turístico y recreativo regional: Parque Lota, Chiflón del Diablo, los pabellones, central Chivilingo, feria, Fuerte Viejo ${ }^{11}$.

Entonces, en lo que nos convoca desde la antropología, y en perspectiva de tiempo largo, debe observarse que en las culturas mineras urbanas la vida de la población mantiene siempre un equilibrio precario o es siempre vulnerable, en la medida que ésta se debe armonizar con la demanda del recurso, la eficiencia, los desarrollos tecnológicos, los ciclos y la rentabilidad de la explotación. Es decir, conjugar el proyecto de vida y su localización con una sensibilidad industrial que no es controlable, lo que obliga a una relativa concordancia y armonía entre el tiempo industrial con el tiempo familiar, cuestión que no es fácil. Por ello, tanto en la explotación del carbón, del nitrato y del cobre, los cambios producto de sus ciclos y las nuevas formas de trabajo trastornan y desordenan a las culturas en sus singularidades, generando procesos de siniestración de las vidas individuales y colectivas.

Esta siniestración corresponde a un tipo particular de sufrimiento, en el que colisiona lo subjetivo inscrito dentro del proyecto vital con la racionalidad industrial. Se manifiesta un sufrimiento dado por la falta de armonía y contradicción entre aquello que es pensado en la larga duración, con seguridad permanente, con cierta infinitud por hombres y mujeres, como es su proyecto vital $\mathrm{y}$, por otra, la ciudad minera cuya existencia no es más que una experiencia temporal finita y efímera que depende de factores que no pueden manejar los habitantes y en los cuales se pierde la interlocución con el 
empleador. En sentido estricto, por una parte tenemos una experiencia temporal que permite un sentimiento de apropiación, de situarse en la ciudad como lo demuestra la historia, de aprehenderla y vivirla, recorrerla y padecerla: es mi casa, mi barrio, mi cuadra, mi almacén, mi plaza; y, por otra, unas fuerzas que están más allá del propio control, que sobrepasan a las generaciones y las creencias que dieron origen a la formación del complejo urbano y a la cultura de la ciudad.

Esto es lo que el trabajo de campo permite registrar en forma testimonionial:

El pampino nunca se va a terminar, él tiene raíces grandes y fuertes que nadie las va a cortar, podrán quitarnos el campamento, podrán quitarnos todo...pero el orgullo de ser pampino y haber nacido en esta tierra jamás en la vida. Nacimos como pampinos y moriremos como pampinos. Mi María, si yo soy nacido y criado aquí, aquí nacieron mis hijos...donde yo voy digo que soy de María Elena, eso se los inculqué de niñitos a mis hijos, donde nació, reconocer sus raíces y nunca negarlas. Si yo negara a María Elena es negar mis raíces, a mi madre. Estoy orgulloso de ser pampino ${ }^{12}$.

La manifestación del ciclo minero altera de manera inmediata a la demografía, al trabajo, a la arquitectura, a la interlocución, a la sociabilidad, lo que se traduce en un desinterés por la inversión pública y privada dentro de la ciudad y conduce a una notable diferenciación entre generaciones y una obsolescencia y decadencia de las identidades laborales.

Con el decaimiento de las ciudades se contrae y reestructura el proyecto vital en sus formas de reproducción biológica, social y espacial, lo que afecta muy rápidamente los volúmenes de la arquitectura ya que pierden su prestancia y su función originaria, así como la vida y la actividad que le da sentido, "el equilibrio entre naturaleza y espíritu que representaba la arquitectura cede a favor de la naturaleza" (Simmel 2001:182). La decadencia de las edificaciones y el abandono de muchas de ellas corre en paralelo a la devaluación de la forma de trabajo y de la proyección local para desarrollar un proyecto familiar. Así, a la ruina en términos materiales, le acompaña un sentimiento paralelo de pérdida que obliga a reestructurar la vida, a pensarla en otros lugares, cuando se puede, o a aferrarse al "mito de la grandeza" y de la contribución de su sociedad al engrandecimiento del país, para sobrellevar la contradicción entre la vida propia y lo que ocurre en la ciudad y la actividad.

Las Company Towns fueron una necesidad para atraer a la población, las que debieron conjugar, dentro del autarquismo y autosuficiencia que desarrollaron, formas especializadas de trabajo, de asignaciones de vivienda, de servicios alimentarios, recreacionales, sanitarios y educativos, es decir, a veces en exceso o en sobreabundancia, todo lo requerido para estabilizar a la población. Sin embargo, los ingentes desarrollos tecnológicos son los que entran a cuestionar el saber hacer de las poblaciones mineras tradicionales y las van dejando poco a poco en una condición de fuera de lugar, al margen, como residuales, ya que cada vez se requieren menos trabajadores y que estén más calificados para las actividades extractivas y productivas.

En el caso de Sewell la salida fue el cierre del emplazamiento. Hoy, desde el 2006, es considerada "Patrimonio de la Humanidad" por la UNESCO en virtud de su ejemplaridad como ciudad industrial del siglo XX. En el caso de la ciudad de Lota, las minas de carbón se cerraron el año 1997, con ello se puso fin de manera definitiva a la actividad extractiva, cerrando los piques, rematando la maquinaria e inundando de agua los túneles que avanzaban unos 20 kilómetros bajo el océano. La alternativa para una ciudad donde sus actuales 50.000 habitantes vivían en torno al trabajo carbonífero, fue un plan de reconversión laboral, el que fracasó en gran medida por la poca ductilidad de la especialización carbonífera y el bajo interés por reemprender otras actividades.

Desde que se decretó el cierre de las minas y el fin de las actividades por parte de la empresa ENACAR $^{13}$, una empresa del Estado, son actualmente unos 4.000 los empleos subsidiados por el Estado, pero ninguno de carácter productivo. Los ex trabajadores deambulan y no se interesan en ninguna otra actividad, tampoco quieren moverse de su ciudad; su vida es en Lota y el imaginario se ubica en la mina. Todo es considerado de segundo orden; los hombres se quedaron sin disciplina laboral, porque no hay lugar para su saber hacer; ya que cuando se cerró la mina "muchos mineros no atinaban a nada, quedaron estáticos, no creían, no se daban cuenta de lo que estaba sucediendo. Estaban como idos, como noqueados" (Carrasco 
et al. 1999:25), lo que demuestra la intensidad de la ruptura con su cotidiano.

A partir del cierre de las minas y de la instalación de los empleos de emergencia se les inculcó una forma de trabajo que no tiene que ver con nuestra historia. Aquí hay gente que trabaja dos horas diarias. Hay gente que trabaja dos días y descansa diez días ${ }^{14}$.

La ciudad de Lota sintetiza la condición objetiva y subjetiva del daño y la exclusión social y la concatenación entre desempleo y decadencia urbana y barrial (Figura 6).

$\mathrm{Al}$ analizar los casos enunciados, donde todo lo acontecido debe ser considerado como una agresión a la biografía, se observa que se destacan la orientación pragmática de la empresa y la emergencia de las condiciones de un mercado plural de trabajo moderno, el que se define por no tener tradición. Es decir, existe una obligación de problematizar el cómo se resuelven las contradicciones de la existencia diaria, con toda su carga valórica, simbólica y afectiva, con una necesidad de explotaciones eficientes cuando el mineral puede mantener vigencia y demanda estable.

Claramente los cambios generados por este sistema de posiciones, al cual están adscritas las ciudades monoproductoras, cuando sobrevienen las crisis, sean estas temporales o definitivas, implican: (a) que en los casos extremos desaparece un mundo de referencia, el de la mina, (b) que desaparece en términos efectivos su profesión, el ser minero, (c) que se produce una dispersión de la comunidad tradicional, (d) que la vida debe reorganizarse en función del desorden de la identidad social de la comunidad de trabajo y (e) que eventualmente puede hasta desaparecer el lugar. Entonces, como proceso de cambio, se ha de observar analíticamente cómo las personas que deciden "permanecer" o "pueden permanecer" en las ciudades, reelaboran sus vidas como herederas y portadoras de una memoria específica, cómo reflexionan y repasan su proyecto de vida a través de la retrospección del pasado y reordenan su tiempo presente.

Desde el punto de vista de la antropología, la cuestión es relevante. Se trata de un cambio profundo, sin retorno, del fin de los modos de ser y hacer, de mundos que se extinguen. Se trata, en resumidas cuentas, de la siniestración de la vida en la medida que se queda instalado en un "nuevo modo de vida" con pérdida de protecciones sociales y de la noción de futuro. Desaparece la cualidad del saber hacer y, con ello, se van los presupuestos emocionales compartidos, la épica, las palabras que nombran realidades y las formas y lugares por donde circulan sus ideologías; se redefinen los ritos de pasaje a través de los cuales se socializan las formas específicas de ver y actuar en el mundo, se pierden las connotaciones.

Tenemos ciudadanos "extirpados de sus antiguas pertenencias" (Déotte 1998:73) porque lo que se juega en la proximidad de las relaciones con los objetos, la arquitectura, el trabajo, las rutinas, las prácticas, es el aprendizaje o el "saber usar" las cosas e instituciones del mundo en el que se ha configurado la biografía (Heller 2002:42).

Una vez producido el quiebre con el subsuelo de ideas que sustentan la vida, se impone la idea de cómo la sociedad se escinde en su saber cotidiano, en la medida que la escasa flexibilidad del saber

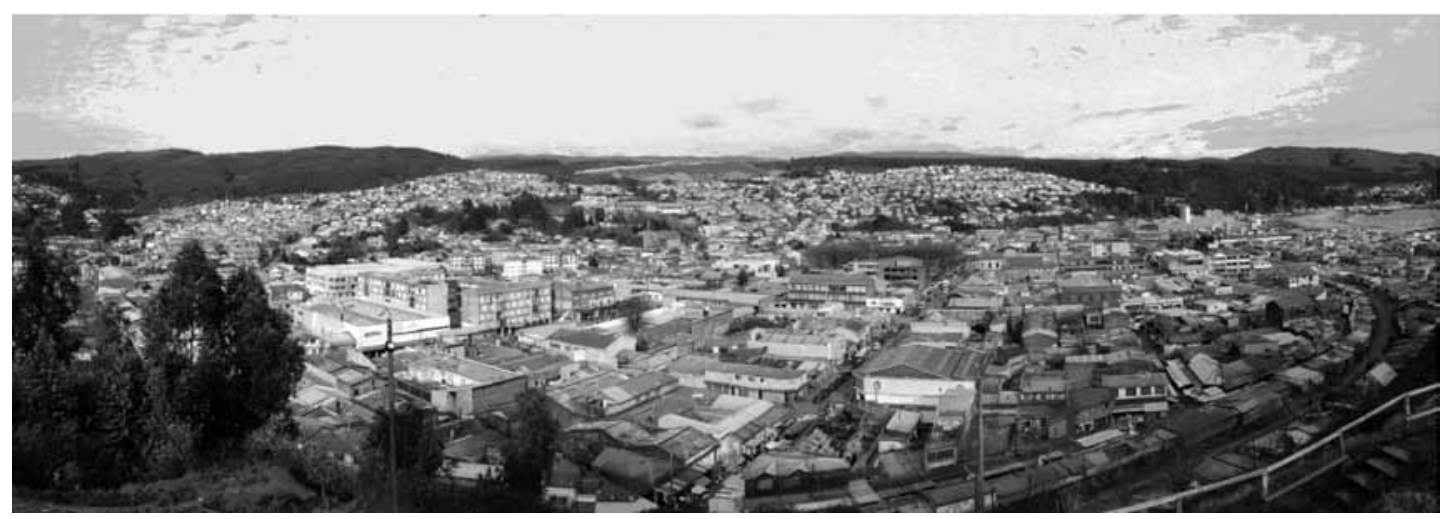

Figura 6. Vista de la ciudad de Lota. Registro de los autores.

View of the city of Lota. From the records in possession by the authors. 
hacer y sus usos, de su relación con las cosas y las instituciones, a los mayores los deja en una condición de pasado, mientras que, a los más nuevos y a los más jóvenes, los que no deben su vida en exclusiva a esa experiencia y saber hacer, pueden manejar una expectativa y un repertorio que les permite un adelante, es decir, un ir hacia el futuro. Muy claramente, el cambio del saber hacer cotidiano obliga a tomar en préstamo un saber asociado a otras experiencias, lo que termina imponiendo un tropismo que presentará otros bloqueos y otras brechas propias de toda búsqueda de un lugar para poder reconciliarse con la propia biografía. La distancia generacional, así como arroja a caminos contradictorios, abiertos e inciertos, también es un cambio de lenguaje para nombrar la esperanza, porque lo antiguo se exilió.

\section{Comentarios Finales}

Los imaginarios son contrarios a la ruina, al abandono y al decaimiento del tejido social, ya que éstos movilizan y comportan una forma de esperanza, instalan un cierto deseo, un proyecto que se anuda, en el caso particular de la minería, a un tropismo citadino sobre el cual discurre el sentido de la vida.

Por eso, el imaginario no corresponde a la imagen detenida o a una situación completa y cerrada, sino a un proceso de creación continua e indeterminada de formas, figuras e imágenes móviles y dinámicas a partir de las cuales es posible referirse a los fenómenos (Castoriadis 1985). El imaginario no se refiere a lo real, ni remite a ello, ni instala una nueva presencia; es matriz de sentido, su efecto orienta la vida cotidiana y se hace sentir en ella, por lo que relaciona elementos cognitivos y de memoria. Un imaginario habla de una condición específica: los hombres y mujeres se ponen de cara al futuro y lo sueñan a su manera, de ahí que pueda hablarse de un proyecto de vida y observar las características específicas del ciclo vital de las poblaciones especializadas como las mineras urbanas.

Además, estos imaginarios colectivos se diferencian de los individuales porque requieren ser institucionalizados y legitimados socialmente (Márquez 2007:80), por eso, a pesar de su relativa autonomía, jamás están exentos de historicidad, de coyunturas, de un lenguaje, de un reclamo y cada gran época y lugar, como los que observamos para el caso de Lota, Taltal, Sewell, María Elena, Pedro de Valdivia y Chuquicamata, entendidos como lugares en los que decantan las relaciones, la identidad y la historia; contienen uno o varios paradigmas imaginarios $^{15}$ (Baeza 2000). Los imaginarios se ubican en esta frontera de lo deseado y lo perdido, lo visible y lo invisible, ya que ellos señalan las tensiones y maneras de enfrentar la vida en comunidad. Éstos marcan la ciudad y la manera de percibirla, de moverse, habitarla y apropiarla, orientan e influyen en las decisiones de las personas, son dinámicos, no se cuestionan y devienen de prácticas sociales y discursos. Preguntarse por estos imaginarios de la ciudad exige por tanto, interrogarse por estas construcciones fundacionales que contribuyen o contribuyeron a hacer inteligible la experiencia de vida en la ciudad minera. Por ello, los imaginarios nos hablan siempre de utopía y de deseo, de eutopías que marcan los proyectos individuales y colectivos (Medina 2010), nos hablan de cómo los que la habitan y también los que narran y describen la ciudad imaginan e inventan formas posibles de vida urbana para crear su ciudad: la ciudad imaginada, la ciudad subjetiva, habla de utopías y de una ciudad ideal, a la manera como lo hicieron los pensadores utópicos (Márquez 2007), lo que también nos conduce a un encuentro con los afectos y los sentidos de la ciudad vivida y proyectada.

En síntesis, las ciudades mineras referidas siempre van aparejadas con la construcción de imaginarios que actúan como matrices de sentido que hacen comprensibles sus derroteros, son cartas de navegación que fundamentan la acción de los sujetos y actores sociales, enriquecen y complejizan la razón, haciéndola deambular entre la realidad y la fantasía. El imaginario se presenta no como una gramática ordenada de inteligibilidad del universo experimentado, sino como una composición relativamente libre e irrefutable, sinuosa y subjetiva, en la medida que no ha de rendir cuentas a ningún tipo de racionalidad o lógica. Lo imaginario tiene que ver con estar en unas creencias y la trama esencial del creer (Baeza 2000), y el creer, en este caso, siempre peca de olvido: las ciudades mineras no dependen de sí mismas, no son autosuficientes, dependen de la posición que éstas tengan en una economía internacionalizada, de las decisiones de otros, de accionistas dispersos (Rodríguez 2010).

Así, si el proyecto de vida está unido, como lo fue por décadas, a la ciudad, éste es vulnerable, móvil, sujeto a agresión y a reescritura.

Es en estos términos que las transformaciones de la economía chilena han puesto históricamente 
en escenarios críticos ciertas continuidades fundamentales de la sociedad y de comunidades especializadas, marcando un corte con el pasado de algunos sectores productivos, abriendo paso a la marginalización creciente de un importante sector de los trabajadores. Por ello, la pregunta por la utilidad de los viejos saberes en los nuevos esquemas productivos es una pregunta recurrente en estos procesos de reconversión hacia una economía de la experiencia y de la patrimonialización. Para las poblaciones marginalizadas de los viejos aparatos productivos en crisis -en cualquiera de las formas descritas-, la pregunta por la continuidad en el ejercicio de un "saber hacer" está siempre presente. De este modo, cuando la inserción social no se asegura más que por el trabajo o el ejercicio de un oficio en una organización, el paso a la crisis de sentidos identitarios (definición de sí mismo y de proyecto) es inevitable, como también parece ser inevitable la declinación de la ciudad y el espacio, para crear otro: el patrimonial.

Cuando se hace evidente la ruptura de la sociabilidad, aflora la nostalgia, un ir y venir hacia el pasado y desde el pasado al presente, porque hay cuestiones fundamentales que no pueden ser suplidas. La nueva segmentación "me deja" y "nos deja" sin nombre, sin posición definida dentro de una comunidad, sin sistemas de referencia, contemplando la declinación de lo cercano. Por eso, como sostiene José Bengoa (2006:57-67), detrás de estos procesos cristalizados en fragmentaciones, en comunidades rotas, relictus o reconstruidas, hay un reclamo de identidad que conduce a la memoria, es decir, a los recuerdos. Pero éstos no refieren necesariamente a los hechos, sino a "los recuerdos que conservamos de éstos". Y ello no habla sino de un tiempo en el que se vivía con determinada certeza, con una dignidad y reconocimiento que ya no está más.

En paralelo y en relación a la ciudad, "hay pocos lugares de retorno que permanezcan idénticos. La ciudad es tiempo presente. Incluso su pasado sólo puede ser vivido como presente. Lo que se conserva del pasado en ella queda incrustado en lo que ella muestra como pura actualidad" (Sarlo 2009:148).

Así, la ruina toma su lugar; la ruina suple a la actividad cotidiana. Conforme aparece la ruina de la ciudad, aparece la declinación de los proyectos vitales, la ruptura de los universos conversacionales y el cuestionamiento del imaginario. Es evidente que al menos dos cosas iniciales se bloquean: el traspaso del saber y del oficio de minero de padre a hijo y la transformación de toda una organización social y económica en torno a la minería.

Entonces, en este sensible espacio de interconexión entre el ciclo de vida de la explotación minera, el destino de la ciudad y los proyectos de vida personal, ocurren, en primer lugar, el reclamo y la demanda sobre las pertenencias, lo que metafóricamente corresponde al equipaje de la existencia y, en segundo lugar, respecto de la participación, en cuanto todo acto personal y colectivo ha tenido impacto sobre esos tres indisociables ejes. Así, los trabajadores mineros centran sus demandas a partir de procesos irreversibles, aunque sustentados en la trayectoria de luchas de la organización sindical y laboral, siendo la cotidianeidad la que da sustento a la continuidad de los roles como proceso específico de socialización.

Es una comunidad que se apaga, que no puede regresar a sus claves fundantes, porque la ciudad real ha borrado las huellas al poner fin a sus rutinas. Si observamos las trayectorias de las ciudades aludidas en relación a lo que son los proyectos de vida, han de observarse tres niveles de reflexión: (a) la ruptura, (b) lo que se pierde y (c) cómo se convive con aquello que es materialidad y que ha perdido su función o los vestigios de una explotación y riqueza que ayudó a construir la propia vida como proyecto vital.

Hablamos de las resonancias, ecos y de cómo se reconstruye y rearticula la vida, a veces desalojada físicamente del mundo que se ayudó a construir. $\mathrm{La}$ experiencia del deterioro de la ciudad y del proyecto vital obliga a revisar el contenido de la propia vida a través de los particularismos urbanos y de sus gentes; evaluar la ruptura, continuidad y sentido de las experiencias; definir nuevos derechos, negociarlos o reinventarlos. La cuestión es qué logra permanecer en estas culturas y cuáles son los elementos que pueden hablar de una cierta continuidad o de las honduras de una gran transformación que dejó a sus espaldas los mitos fundacionales y la épica de mil batallas con que se construyó el espacio de lo local y sus reconocimientos nacionales.

Pero, como sostiene Antonio Tabucchi (1999:55) el principio de una historia es sólo la continuación de otro principio.

Agradecimientos: Agradecemos los comentarios y sugerencias de los evaluadores de este texto. 


\section{Referencias Citadas}

Anderson, B. 2002. Comunidades Imaginadas. Reflexiones sobre el Origen y la Difusión del Nacionalismo. Fondo de Cultura Económica, Buenos Aires.

Archuf, L. (comp.) 2002. Identidades, Sujetos y Subjetividades. Prometeo Libros, Buenos Aires.

Baeza, M. 2000. Los Caminos Invisibles de la Realidad social: Ensayo de Sociología Profunda sobre los Imaginarios Sociales. Editorial Sociedad Hoy-RIL, Santiago.

Barraza, E., E. Castro y S. Mansilla 1992. Naturaleza e historia en textos mineros de la generación del 38. En Mundo Minero. Chile, Siglos XIX y XX, editado por M. Orellana y J. Muñoz, pp. 7-29, Universidad de Santiago de Chile, Santiago.

Bengoa, J. 2006. La Comunidad Reclamada. Identidades, Utopías y Memorias en la Sociedad Chilena Actual. Catalonia, Santiago.

Cardoso de Oliveira, R. 2007. Etnicidad y Estructura Social. Ciesas-UAM, Universidad Iberoamericana, México.

Carrasco, A. y M. E. Vega 1999. Cuando la Luz se Apaga. El Día que se Cerró la Mina de Lota. LOM Editores, Santiago.

Castoriadis, C. 1985. La Institución Imaginaria de la Ciudad. Volumen 1. Tusquets, Barcelona.

Corvalán, G. 1992. Modo de vida de los mineros del carbón. Golfo de Arauco. En Mundo Minero. Chile, Siglos XIX y XX, editado por M. Orellana M. y J. Muñoz C., pp. 125-150, Universidad de Santiago de Chile, Santiago.

Déotte, J.-L. 1998. Catástrofe y Olvido. Las Ruinas, Europa y el Museo. Editorial Cuarto Propio, Santiago.

Di Tella, T., L. Brams, J.-D. Reynaud y A. Touraine 1966. Huachipato et Lota: Etude sur la Conscience Ouvriere dans deux Entreprises Chiliennes. Editions du Centre National de la Recherche Scientifique. Paris.

Evans-Pritchard, E. 1977. Los Nuer. Editorial Anagrama, Barcelona.

Garcés, E. 1999. Las Ciudades del Salitre. Editorial Orígenes, Santiago.
- - - 2007. Las Ciudades del Cobre. Ediciones Universidad Católica de Chile, Facultad de Arquitectura, Diseño y Estudios Urbanos, Santiago.

Heller, Á. 2002. Sociología de la vida cotidiana. Ediciones Península, Barcelona.

Márquez, F. 2007. Imaginarios urbanos en el Gran Santiago: huellas de una metamorfosis. Revista Eure XXXIII:79-88, Santiago.

Medina, P. 2010. La espera como forma alienada del sufrimiento humano. La historia interrumpida de un pueblo minero. En Duelo, Pérdida y Separación: Figuras del Sufrimiento Humano, editado por A. Bilbao e I. Morlans, pp.117-128. Ediciones Universitarias de Valparaíso, Valparaíso.

Rodríguez, J.C. 2010. De la ciudad del trabajo a la ciudad del vacío: el lugar del sufrimiento. En Duelo, Pérdida y Separación: Figuras del Sufrimiento Humano, editado por A. Bilbao e I. Morlans, pp. 91-106. Ediciones Universitarias de Valparaíso, Valparaíso.

Rodríguez, J. y P. Miranda 2008. Tiempo industrial y tiempos sociales en María Elena, la última ciudad del salitre. Chungara Revista de Antropología Chilena 40:81-97.

- - - 2010. Identidad, transformación y retórica patrimonial en una ciudad minera del Desierto de Atacama, Chile. Revista Desacatos 33:151-166, México DF.

Rodríguez, J., P. Miranda y P. Mege 2005. Réquiem para María Elena: notas sobre el imaginario de los últimos pampinos. Estudios Atacameños 30:139-167.

Sarlo, B. 2005. Tiempo Pasado. Cultura de la Memoria y Giro Subjetivo. Una Discusión. Siglo XXI Editores, Buenos Aires.

- - -2009. La Ciudad Vista. Mercancías y Cultura Urbana. Siglo XXI Editores, Buenos Aires.

Simmel, G. 2001. Sobre la Aventura. Ensayos de Estética. Ediciones Península, Barcelona.

Tabucchi, A. 1999. El Ángel Negro. Editorial Anagrama, Barcelona.

Tomes, Z. 2008. Applying the life-cicle theory. The rise and fall of railways. The Journal of Transport History 29:120-124.

\section{Notas}

1 Este artículo se ha realizado en el contexto del Proyecto FONDECYT 1095037, Memorias, Imaginarios y Ruinas en las Ciudades de la Utopía Industrial: Lota y Taltal.

2 La figura del empleador siempre es doble: asegura y sanciona, da y priva, "me necesita pero me larga".

3 Cada sector poblacional está definido por una posición jerárquica dentro de la empresa.

4 Muy claramente dentro de los registros orales, fluye con extrema recurrencia la alusión a la figura superlativa de los hospitales de Chuquicamata, de María Elena y de Pedro de Valdivia.

5 Entrevista realizada en trabajo de campo en Lota, durante 2010.

6 Entrevista realizada en trabajo de campo en Lota, durante 2010.
7 La idea del ciclo de vida está tomada del trabajo de Zdenek Tomes (2008), en el que desarrolla cuál ha sido el comportamiento de la expansión del ferrocarril hasta nuestros días, observando sus momentos de bonanza y declinación.

$8 \quad$ El Estado de Chile adquirió en 1967 el 51\% de la propiedad accionaria de la Braden Copper Co., en el camino de lo que sería la posterior nacionalización de la Gran Minería en 1971.

9 Entrevista realizada en trabajo de campo, 2008.

10 Entrevista realizada en trabajo de campo, 2007.

11 Entrevista realizada a Vasili Carrillo, Jefe de Gabinete de la Ilustre Municipalidad de Lota, 2009.

12 Entrevista realizada en trabajo de campo, 2007.

13 Empresa Nacional del Carbón. 
14 Entrevista realizada a Vasili Carrillo, Jefe de Gabinete de la Ilustre Municipalidad de Lota, 2009.

15 Resulta emblemático el caso de Lota, ya que puede rastrearse a la organización sindical como el motor del imaginario, la que en permanentes movilizaciones y huelgas durante el siglo XX como las de 1920, 1946 y 1960, alteraron el presente, visionando, por una parte, una sociedad sustentada en principios de organización y sociabilidad socialistas y comunistas, y por otra, la necesidad del control del carbón como riqueza básica para mejorar en la ciudad las condiciones de vida y trabajo de hombres y mujeres. 